\title{
Specificity of high-pure monocrystalline silicon production for various registering and converting devices
}

\author{
Yu.V.Trubitsyn, S.V. Zverev \\ State research and design Titanium institute, Ukraine, Zaporozhye.
}

\begin{abstract}
In this paper, recent results of studies focused on detector-grade silicon monocrystals production are summarized and systematized. Described are the manufacturing technology of silicon rod with a diameter up to $105 \mathrm{~mm}$ and dislocation-free monocrystals used for fabrication of large area detectors, $p$-type conductivity crystals with resistivity more than $1000 \mathrm{Ohm} \cdot \mathrm{cm}$ being prepared by the method of neutron-transmutation doping.
\end{abstract}

Keywords: silicon, monocrystal, detector, floating zone method, neutron-transmutation doping.

Paper received 08.10.99; revised manuscript received 21.12.99; accepted for publication 21.03.00.

More then 25-year experience of scientific studies and engineering developments for monocrystalline detectorgrade silicon production are accumulated in Ukraine.

High-pure silicon monocrystals used for fabricating detectors and photodetectors of radiations get solely by float-zone melting (FZ), and these have a resistivity not less than $1000 \mathrm{Ohm} \cdot \mathrm{cm}$ of $n$ - and $p$-types conductivity. The concept of "high-pure" silicon monocrystals includes not so hard requirements to the minimum value of resistivity, but has some restrictions on concentrations of electrically active impurities $B$ and $P$ must not exceed $1 \cdot 10^{13} \mathrm{~cm}^{-3}$, $\mathrm{O}$ and $\mathrm{C}$ impurities, namely: not more $5 \cdot 10^{16} \mathrm{~cm}^{-3}$, heavy, alkaline and lanthanide elements $5 \cdot 10^{13} \mathrm{~cm}^{-3}$. Besides, any success in applying this material to the devices is determined by high homogeneity in bulk distribution of these impurities, high value of minority charge carrier lifetime, perfection of crystalline structure.

Since discovery of ionization effect in solids in 1955 and realization of possibility to use semiconductor materials as detectors of elementary particles, the requirements to purity of monocrystals increased over all afore-mentioned parameters. So, if at the beginning of 60 s to highpure silicon one can refer monocrystals with dislocation structure and 10-200 Ohm. $\mathrm{cm} n$-type conductivities, at the end of 60 s and beginning of 70 s resistivity of highpure silicon went up to $3000-6000 \mathrm{Ohm} \cdot \mathrm{cm}$, and monocrystals grew without dislocations and with control- led fine structure - A- and B-type microdefects. At present, come into being the production of $p$-type conductivity monocrystals with resistivity more than $10000 \mathrm{Ohm} \cdot \mathrm{cm}$ and $n$-type with resistivity more than $3000 \mathrm{Ohm} \cdot \mathrm{cm}$ with controlled separate concentrations of electrically active impurities, neutral impurities and having high value of minority charge carrier lifetime.

In this work, results of studies for detector-grade silicon monocrystals production, carried out on Zaporozhye Titanium \& Magnesium Plant (ZTMP), in the floating zone melting labs are systematized.

Polycrystalline silicon used as source material for detector silicon get by the method of thermal decomposition of monosilane and/or the Siemens process in accordance with generalized reactions of the Siemens process:

$$
\mathrm{SiHCl}_{3}+\mathrm{H}_{2} \rightarrow \mathrm{Si}+3 \mathrm{HCl}
$$

and for the method of thermal decomposition of monosilane:

$$
\mathrm{SiH}_{4} \rightarrow \mathrm{Si}+2 \mathrm{H}_{2}
$$

Both methods in their own technological cycles include special ways for deep purification of source components from impurities - low-temperature and reactionary rectification, distillation, thermophorez, ion purification.

Contents of impurities in source polycrystalline silicon and requirements for given final compound and for 
impurity distribution set conditions for float-zone purification, preprocessing condition of rod and after-treatment of monocrystals [1,2].

Specially for high-pure silicon monocrystals growing float zone units "Crystal 109" and "Crystal 109M" are designed and made. In these units double unoil compactions for chamber lid and all rolling parts are applied. There are no gas emitting, non-cooling sections and details inside the chamber, any places are accessible for cleaning. As a result, chamber backgrounds are decreased nearly by order of magnitude less in contrast with rest nonsingle-purpose equipment to $(1-0.5) \cdot 10^{12} \mathrm{~cm}^{-3}$.

The requirements to polycrystalline silicon, suitable for high-pure silicon monocrystals production with presence of two impurities in it - boron and phosphorus, it is possible to express as follows:

for $p$-type of conduction

$$
\begin{aligned}
& N_{B}=N_{\text {rear }}\left(\frac{1}{1-\gamma}\right), \\
& N_{P}=N_{B}\left(\frac{\gamma-k^{n}}{k^{n}}\right),
\end{aligned}
$$

for $n$-type of conductivities

$$
\begin{aligned}
& N_{B}=N_{\text {rear }}\left(\frac{\gamma}{1-\gamma}\right), \\
& N_{P}=N_{B}\left(\frac{1 / \gamma-k^{n}}{k^{n}}\right),
\end{aligned}
$$

where $N_{B}$ and $N_{P}$ are maximum possible contents of boron and phosphorus impurities accordingly, $\mathrm{cm}^{-3} ; N_{\text {rear }}$ is a given difference between concentration of boron and phosphorus impurities, $\mathrm{cm}^{-3}$; $\gamma$ is a level of minor impurity compensation; $k$ is a purification efficient factor; $n$ is a number of passes during float-zone purification.

In general, necessary conditions for float-zone purification of the polycrystalline silicon depending on boron and phosphorus contents, given contents of the main dopant and efficiency of used technological circuit is possible to write down:

for $p$-type of conduction

$$
n=\frac{\ln \left(N_{B}-N_{\text {rear }}\right)-\ln \left(N_{B}+N_{P}\right)}{\ln k} ;
$$

for $n$-type of conduction

$$
n=\frac{\ln \left(N_{B}+N_{\text {rear }}\right)-\ln \left(N_{B}+N_{P}\right)}{\ln k} .
$$

Control of concentration and structure of electrically active and neutral impurities is a task of float-zone purification. Checking a contents of the donor and acceptor impurities in each polycrystalline silicon series is realized accordingly by single-pass and multi-pass float zone purification of the tested samples. Measured on these samples resistivity value and a type of conduction are the raw data for using float-zone purification condition to whole polycrystalline silicon series produced in given apparatus by thermal decomposition of monosilane or by the Siemens process.

Demerits of this checking method are: inevitable entering of contamination during samples fabrication; impossibility of the accounts of impurity distribution heterogeneity along the rod and from rods to rods between series; losses of silicon during selection of samples for checking; measured resistivity values of single-pass sample and multi-pass sample give information only upon difference between concentrations of donor and acceptor impurities.

Using a contactless microwave method $[3,4]$ for measurements of the resistivity of polycrystalline silicon rods before its float-zone purification allows taking into account impurity distribution heterogeneity in each rod and inserting an appropriate correction to the purification condition. In this case expressions (7) and (8) will take a look:

for $p$-type of conduction

$$
n=\frac{\ln \left[\frac{364,5 \rho_{i}\left(\rho_{\text {rear }}-\rho_{M P}\right)}{\rho_{\text {rear }}\left(364,5 \rho_{i}+480 \rho_{M P}\right)}\right]}{\ln \left[0,57 V^{0,54} \exp (-0,1 V)+\frac{\ln (1,76 / f)}{1,875 V+5,55}\right]},
$$

for $n$-type of conduction

$$
n=\frac{\ln \left[\frac{\rho_{i}\left(364,5 \rho_{\text {rear }}+129,6 \rho_{M P}\right)}{\rho_{\text {rear }}\left(364,5 \rho_{i}+480 \rho_{M P}\right)}\right]}{\ln \left[0,57 V^{0,54} \exp (-0,1 V)+\frac{\ln (1,76 / f)}{1,875 V+5,55}\right]},
$$

where $\rho_{i}$ is a resistivity of $i$-th polycrystalline silicon rod, measured by microwave method, Ohm $\cdot \mathrm{cm} ; \rho_{M P}$ is a resistivity of checked sample after multi-pass FZ purification (contents of boron impurity), $\mathrm{Ohm} \cdot \mathrm{cm} ; \rho_{\text {rear }}$ is a given resistivity value $\mathrm{Ohm} \cdot \mathrm{cm} ; V$ is a velocity of zone moving during purification, $\mathrm{mm} / \mathrm{min}$; $f$ is an inductor frequency, $\mathrm{MHz}$.

Technology of silicon rod with diameter up to $105 \mathrm{~mm}$ with multi-pass FZ purification without opening a chamber having no foreign analogs is designed and mastered. It has allowed obtaining dislocation-free monocrystals, used for fabrication of large area detector.

The dislocation-free monocrystals growth is produced both in vacuum and in gas ambience - argon, argon and hydrogen mixtures. During the growth in gas atmosphere, the deep purification of argon from impurities of oxygen, moisture, hydrocarbons, nitrogen up to concentrations not more than $1 \mathrm{ppm}$ is used. With this aim, a high-efficiency purification equipment is used, and for production of the detector-grade silicon - an individual final argon purification is used too. Gasodynamics of ambiences in the course of growing play a significant role during monocrystal production in protective atmosphere. Pro- 
tective atmosphere should be considered as an impurity transporter from internal areas of chamber surfaces and technological rig. It proves to be true if considering results of measurements of minority charge carrier lifetime value in monocrystals grown in the argon flow under different their pressures in chamber, given in the Picture.

Moreover, reproducibility of initial resistivity for high-resistance silicon monocrystals after the FZ-process in gas atmosphere also appeared to be rather sensitive to such factors as a time of staying an open chamber in the air and ways of chamber dehermetization after the growing process. During the chamber dehermetization the atmospheric air, air moister and dust are adsorbed on its internal surfaces. In Table 1 the contents of oxygen in argon at the FZ apparatus chamber's entrance and exit after its hermetic sealing is given depending on time of staying in air. The results given in the Table 2 demonstrate a process of washing away of oxygen impurity by the argon flow from chamber's surfaces after their preliminary vacuuming. As it is seen from Tables 1 and 2, limiting part is an influence of adsorbing surfaces sources of polluting impurities.

As "know-how" the special sequence of technological operations for preparation and realization of FZ processes in ambient gas is designed, ensuring the minimal contents of oxygen impurity in silicon no more than $1 \cdot 10^{15}$ $\mathrm{cm}^{-3}$ and carbon no more than $5 \cdot 10^{15} \mathrm{~cm}^{-3}$.

The microdefects revealed in dislocation-free silicon monocrystals are distinguished by the size, concentrations, distribution in the crystal and by its behavior during thermoprocessing. In accordance with [5], microdefects are subdivided into 4 types: A, B, C, D. Their formation conditions are connected with parameters of crystal growing.

Aggregate value of growing parameters, ensuring the production of dislocation-free monocrystals with the given type of microdefects, is possible to be expressed with Bio's criterion as follows:

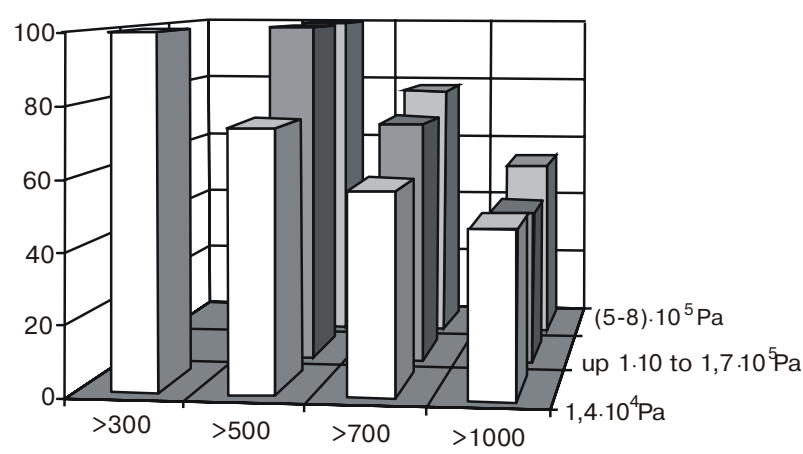

Picture - Distribution of minority carrier lifetime value in FZsilicon monocrystals, \%
Type of microdefects

Range of Bio's criterion A B D
Transformed similarity criterion for float-zone melting conditions is calculated according to the expression:

$$
B_{i}=9,63 \times 10^{2} \frac{L}{\nabla T d^{2}}
$$

where $L$ is crystallization front shape sagging; NT is a temperature gradient; $d$ is a diameter of the crystal.

In the Table 3, recommended main technological parameters, which ensure obtaining the crystals only with D-microdefects, are given.

Further perfecting the parameters of high-pure silicon monocrystals requires an attraction of new methods for production and processing the monocrystals with given parameters when radiation-thermal processes are used.

Jointly with Kiev Nuclear Research Institute, for the first time, developed is the industrial technology of dislocation-free $p$-type conductivity monocrystals production

Table 1. Contents of oxygen impurity in argon under different variants of opening the chamber.

\begin{tabular}{c|c|c}
\hline \hline \multirow{2}{*}{$\begin{array}{c}\text { Time of staying the } \\
\text { chamber in air }\end{array}$} & \multicolumn{2}{|c}{ Concentration of oxygen, ppm } \\
\cline { 2 - 3 } & opening a chamber by argon & opening a chamber by air \\
\hline 300 & $7(3)^{*}$ & $10(3)$ \\
\hline 900 & $10(1,5)$ & $37(2)$ \\
\hline 1800 & $10(2)$ & $35(2)$ \\
\hline $10,8 \cdot 10^{3}$ & $11(2)$ & $34(3)$ \\
\hline \hline
\end{tabular}

* - Parenthetically brought the contents of oxygen in argon at the entrance of chamber

Table 2. The changes of content of oxygen impurity in argon at the exit of FZ chamber with cleaning out by blowing, ppm

\begin{tabular}{llllllll}
\hline \hline Time of cleaning out by blowing of the chamber & 0 & 600 & $1,2 \cdot 10^{3}$ & $1,8 \cdot 10^{3}$ & $2,4 \cdot 10^{3}$ & $3,6 \cdot 10^{3}$ & $7,2 \cdot 10^{3}$ \\
\hline Argon consumption $1,7 \cdot 10^{-5} \mathrm{~m}^{3} / \mathrm{sec}$ & 65 & 46 & 32 & 22 & 16 & 8 & - \\
\hline Argon consumption $3,4 \cdot 10^{-5} \mathrm{~m}^{3} / \mathrm{sec}$ & 76 & 40 & 5 & 1 & - & - & - \\
\hline \hline
\end{tabular}


(with crystal resistivity more than $1000 \mathrm{Ohm} \cdot \mathrm{cm}$ ) by the method of neutron-transmutation doping. New material has shown positive results in IR-radiations photodetectors. Neutron-transmutation doping of high-resistance $p$ silicon was produced both in the variant of partial compensations of the residual boron impurity contents and in the variant of complete re-compensation with the conductivity type inversion. Detailed body of mathematics and results of development are stated in [6].

One of perspective and relatively new direction using the method of nucleus transmutation is the $\gamma$-quantum doping method. The method is capable to solve a specific task for obtaining the $n$-type silicon with resistivity $\geq 3000$ Ohm $\mathrm{cm}$. Collaboration with the Polytechnic Institute (StPetersburg), Institute of Atomic Energy (Moscow), Physicist-technical Institute (Kharkov) created a base for studies in this area and have allowed to develop an experimental technology of $\gamma$-quantum doping for $n$-type highresistance detector-grade silicon. Comparative features of new and traditional material as well as detectors based on them are shown in Table 4.

High-pure silicon is the main material for producing monolithic detectors of infrared radiation. The sensitivity of silicon within the range of wavelength 1-25 $\mu \mathrm{m}$ depends on abilities of different impurities to form impurity energy levels in the forbidden zone and selectively react to IR-radiation of certain wavelength. The working interval $8-14 \mu \mathrm{m}$ is reached by the introduction to silicon such impurities as tellurium, gallium, bismuth, the most efficient from which is gallium.

Main requirements to such material are high level of doping by gallium $\left(1 \cdot 10^{17} \mathrm{~cm}^{-3}\right)$ and presence of residual boron and phosphorus impurities at a level no more than $10^{12}-10^{13} \mathrm{~cm}^{-3}$ that should be mutually compensated.

The developed technology allows to produce the dislocation-free monocrystals with given orientation, diameter up to $105 \mathrm{~mm}$ and concentration of gallium from $5 \cdot 10^{15}$ up to $3 \cdot 10^{17} \mathrm{~cm}^{-3}$.

After determination of boron and phosphorus concentration by IR-spectroscopy, monocrystals were exposed to neutron-transmutation doping in order to equalize boron and phosphorus concentrations and, in such way, maximize the sensitivity of devices.

An efficient lifetime of majority charge carrier is one of material filtness criteria for device fabrication. The control of this parameter was carried out under $T=10 \mathrm{~K}$, signal frequency $70 \mathrm{~Hz}$, background $8 \cdot 10^{12}$ quantum $/ \mathrm{cm}^{2} \cdot \mathrm{sec}$. Under $E=250 \mathrm{~V} / \mathrm{cm}$ majority charge carrier lifetime exceeded $2 \cdot 10^{-8} \mathrm{sec}$ for $50 \%$ samples, but under $E=400 \mathrm{~V} / \mathrm{cm}$ - for $90 \%$ samples.

Table 3. Constructive and technological parameters that ensured obtaining the monocrystals with D-type microdefects.

\begin{tabular}{|c|c|c|c|c|c|}
\hline $\begin{array}{l}\text { Diameter of a } \\
\text { monocrystal, } \\
\text { mm }\end{array}$ & $\begin{array}{c}\text { Internal diameter } \\
\text { of an inductor, } \\
\mathrm{mm}\end{array}$ & $\begin{array}{l}\text { External diameter } \\
\text { of an inductor, } \\
\mathrm{mm}\end{array}$ & $\begin{array}{l}\text { Rotation velocity } \\
\text { of monocrystal, } \\
\mathrm{mm} / \mathrm{min}\end{array}$ & $\begin{array}{l}\text { Value of crystal- } \\
\text { lization front } \\
\text { shape sagging, mm }\end{array}$ & $\nabla \mathrm{T},{ }^{\circ} \mathrm{C} / \mathrm{cm}$ \\
\hline $25-30$ & 26 & $36-40$ & 6.0 & 2.5 & 130 \\
\hline $30-35$ & 28 & $40-60$ & 5.0 & 3.5 & 120 \\
\hline $35-40$ & 30 & $60-90$ & 4.5 & 4.5 & 100 \\
\hline $45-60$ & 32 & $90-100$ & 4.0 & 6.0 & 80 \\
\hline $60-75$ & 33 & $100-110$ & 3.8 & 8.0 & 60 \\
\hline $75-90$ & 33.5 & $110-120$ & 3.5 & 10.0 & 55 \\
\hline $90-105$ & 34 & $150-200$ & 3.0 & 12.0 & 50 \\
\hline
\end{tabular}

Table 4. Parameters of detectors made from $n$-type high-resistance silicon.

\begin{tabular}{|c|c|c|c|c|c|c|c|}
\hline $\begin{array}{l}\text { Technology } \\
\text { of silicon } \\
\text { production }\end{array}$ & $\begin{array}{l}\text { Resistivity, } \\
\text { Ohm } \cdot \mathrm{cm}\end{array}$ & $\begin{array}{l}\text { Concentration } \\
\text { of redundant } \\
\text { carriers, } \mathrm{cm}^{-3}\end{array}$ & $\begin{array}{l}\text { Resolution for } \\
\alpha \text {-particles }{ }^{239} \mathrm{Pu} \\
(5.4 \mathrm{MeV}), \mathrm{keV}\end{array}$ & $\begin{array}{l}\text { Noise } \\
\text { component, } \\
\text { keV }\end{array}$ & $\begin{array}{l}\text { Gathering } \\
\text { component, } \\
\mathrm{keV}\end{array}$ & $\begin{array}{l}I_{\text {leakage }} \text { with } \\
U=100 \mathrm{~V} \\
\mathrm{~mA}\end{array}$ & $\begin{array}{c}I_{\text {leakage }} \text { with } \\
U=200 \mathrm{~V}, \\
\mathrm{~mA}\end{array}$ \\
\hline $\begin{array}{l}\text { Float zone } \\
\text { method }\end{array}$ & 6300 & $6.3 \cdot 10^{11}$ & 26 & 25 & 8 & 0.59 & 0.9 \\
\hline $\begin{array}{l}\gamma \text {-quantum } \\
\text { doping } \\
\text { method }\end{array}$ & 2400 & $1.7 \cdot 10^{12}$ & 33 & 32 & 8 & 0.73 & 1.0 \\
\hline
\end{tabular}


Yu. V. Trubitsun, S.V. Zverev: Specifity of high-pure monocrystalline silicon ...

\section{Conclusions}

The problem of high-pure monocrystalline silicon production is refered to the "high-tech" sphere. High requirements to such material do not allow its production in conditions of usual quality silicon growth. Organization of its production requires special efforts in part of technological, apparatus and metrological supply of all traditional processes.

\section{References}

1. K.N. Neymark, Yu.V. Trubitsyn, I.F. Chervonyi // Highpure substances, №2, p.134, (1992), (in Russian).

2. K.N. Neymark, Yu.V. Trubitsyn, I.F. Chervonyi // Color metals, №6. p.79, (1992), (in Russian).

3. Yu.V. Trubitsyn, K.N. Neymark, I.F. Chervonyi, // Highpure substances, №3, p.129,(1989), (in Russian).

4. A.c. SU №1422726.

5. N.V. Veselovskaya, E.G. Sheykhet, K.N. Neymark, E.S. Falkevich, Cluster type defects in silicon single crystals // Growing and doping semiconductor crystals and films, Novosibirsk: Nauka, V.2. pp. 284-288, (1977), (in Russian).

6. K.N. Neymark, Yu.V. Trubitsyn, E.S. Falkevich, I.F.Chervonyi // High-pure substances, №2, p.53, (1993), (in Russian). 